\title{
Perinatal Development of the Motor Systems Involved in Postural Control
}

\author{
Laurent Vinay, Faïza Ben-Mabrouk, Frédéric Brocard, François Clarac, Céline Jean-Xavier, \\ Edouard Pearlstein and Jean-François Pflieger $\$$ \\ Centre National de la Recherche Scientifique (CNRS) and Université de la Méditerranée, Laboratoire \\ Plasticité et Physio-Pathologie de la Motricité (UMR6196), CNRS, F-13402 Marseille cx 20, France
}

\begin{abstract}
SUMMARY
Motor behaviors of some species, such as the rat and the human baby, are quite immature at birth. Here we review recent data on some of the mechanișms underlying the postnatal maturation of posture in the rat, in particular the development of pathways descending from the brain stem and projecting onto the lumbar enlargement of the spinal cord. A short-lasting depletion in serotonin affects both posture and the excitability of motoneurons. Here we try to extrapolate to human development and suggest that the abnormalities in motor control observed in childhood-e.g. deficits in motor coordination-might have their roots in the prenatal period, in particular serotonin depletion due to exposure to several environmental and toxicological factors during pregnancy.
\end{abstract}

\section{INTRODUCTION}

At first sight, human and rat development appear to be quite different. This is largely due to

Reprint requests to: Laurent Vinay, CNRS, $\mathrm{P}_{3} \mathrm{M}, 31$ chemin Joseph Aiguier, F-13402 Marseille cx 20, France. e-mail: vinay@dpm.cnrs-mrs.fr

Present address: Département de sciences biologiques, Universite de Montreal, C.P. 6128, Succursale centre-ville, Montréal (Qc) Canada, H3C 3J7 huge differences in the duration of prenatal and postnatal development: the human baby is born after 9 months (270 days) in utero and adulthood is reached at around 20 years, whereas rat development lasts about 6 weeks, 3 weeks before [embryonic day (E) 0 to 21] and 3 weeks after [post-natal day (P) 0 to 21] birth. However, striking similarities can be observed between human and rat motor development when taking a time scale of one day in the rat corresponding to one month in the baby (Fig. 1). Firstly, both are quite immature from a motor point of view at birth. Secondly, development occurs along a rostrocaudal axis. The rat lying in a prone position becomes able to lift its head from the floor on P2 (Geisler et al., 1993), this corresponds roughly to the third month in the baby. From around P5 in the rat, the shoulders are raised from the ground; this is associated with functional maturation of the forelimbs which, drawn under the body gradually, begin to support the weight of the anterior part of the body (Altman et al., 1975). The hindlimbs are not able to support the weight of the pelvis at the end of the first postnatal week in the rat. Support by the paws and the digits is first observed at P10; from P12 onwards the animal can walk (Altman et al., 1975; Geisler et al., 1993; Westerga et al., 1990). Similarly, the human baby starts to walk at around the end of the first year.

Locomotion can be schematically divided into two components. The phasic component is responsible for the rhythmic alternating contractions of limb and trunk muscles, produced mainly by central 

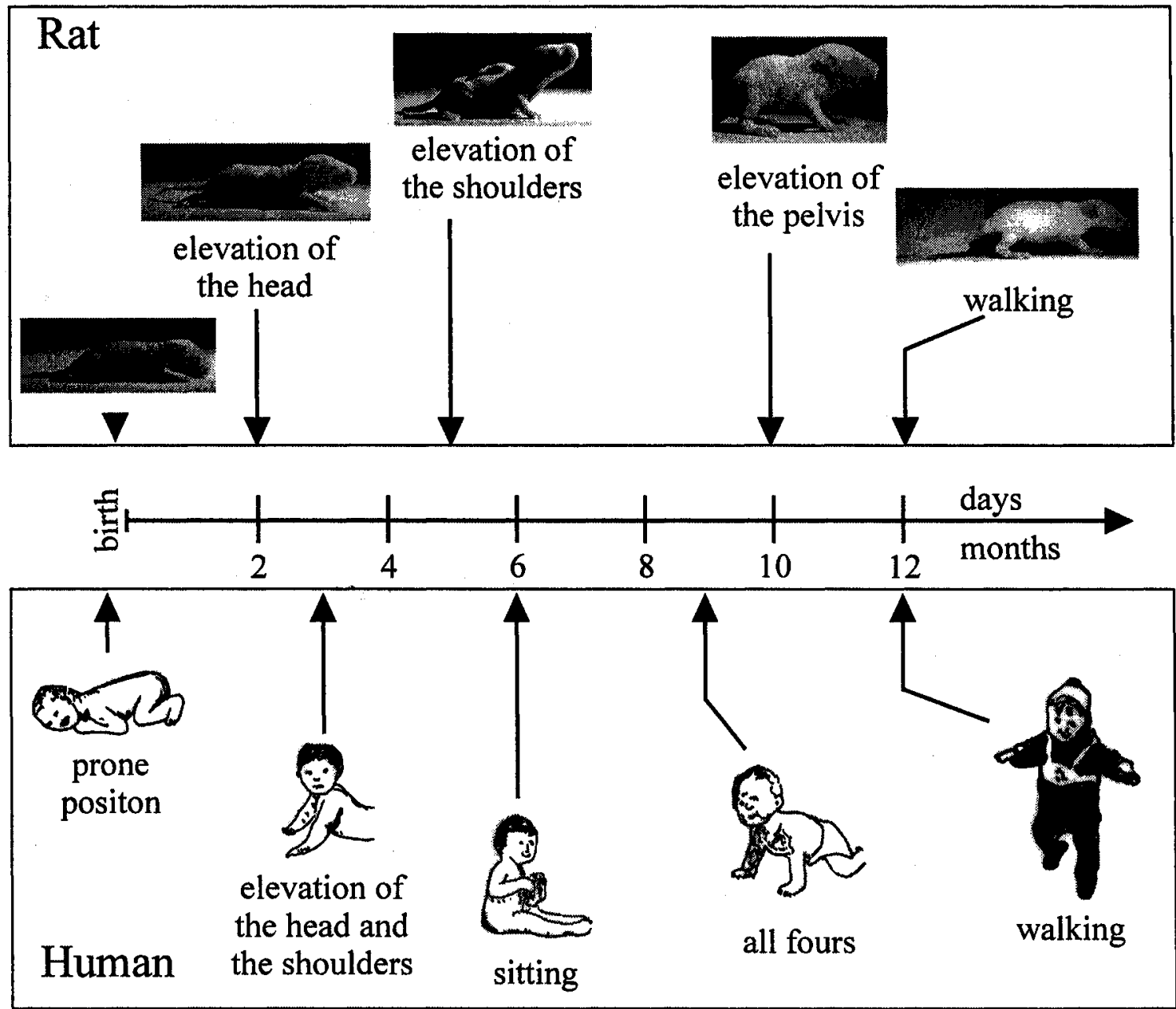

Fig. 1: Schematic comparison between human and rat postnatal motor developments. One day in the rat corresponds roughly to one month in the human baby

pattern generators (CPGs) in the spinal cord (e.g. Grillner, 1981; Rossignol, 1996). The tonic component is associated to the postural muscle tone required for locomotion with the ventral body surface off the floor to occur. Several observations demonstrate that the dynamic componentCPGs-is functional at birth (Cazalets et al., 1990. McEwen et al., 1997). By contrast, the tonic component is quite immature at birth. A significant maturation of postural control occurs during the first postnatal week (Altman et al., 1975). This development depends on the maturation of several systems, such as the musculo-skeletal system, the sensorimotor networks, the higher brain centers, pathways descending to the spinal cord, and the ascending tracts conveying sensory information and efference copy signals to supraspinal nuclei. This review will focus mainly on the development of the tracts arising from the brain stem and projecting to the lumbar enlargement of the spinal 
cord. Most data discussed in this article concern the rat model, but we are tempted to extrapolate to human development, although translating developmental times across species is difficult.

\section{DEVELOPMENT OF DESCENDING PATHWAYS INVOLVED IN POSTURAL CONTROL}

The development of projections descending from the brain to the lumbar cord has been studied by means of anatomical techniques in the rat (Leong et al., 1984; Auclair et al., 1993; Kudo et al., 1993; Lakke, 1997). The first axons reach the cervical cord at the embryonic day (E) 13-14, the thoracic levels one day later, and the lower lumbar levels before birth. Cells of origin of these earliest projections are located in the medullary and pontine reticular formation, in the interstitial nucleus of the medial longitudinal fasciculus, and in the lateral vestibular nucleus. The projections arising from several other nuclei of the brain stem reticular formation that are involved in the control of posture and locomotion (Newman, 1995) reach the upper lumbar cord slightly before birth and the lower lumbar cord during the first postnatal days. The corticospinal projections are the latest to develop and arrive by the end of the first postnatal week (Donatelle, 1977; Schreyer et al., 1982). The pathways starting to project to the lumbar cord before birth are far from being fully developed at that time. It should be recalled that a considerable number of axons continue to arrive in the lumbar enlargement postnatally; for instance only about forty percent of the vestibulospinal axons present in adults are detected in the lumbar cord on the day of birth (Auclair et al., 1993). The adult projection pattern is observed only at the end of the second postnatal week. In additicn, all the ages mentioned above correspond to the detection of axons in the white matter. A period of at least 3 to 4 days should be added to account for the turn of the axon towards the grey matter (Joosten et al.,
1994), the growth into the ventral horn, and finally the formation of collateral branches and functional synapses.

We will now focus on the development of serotonergic projections, although other monoaminergic systems are likely of importance for motor development. Serotonin (5-hydroxy-tryptamine, 5-HT) is contained in groups of neurons in the brain stem (Dahlstrom et al., 1964), some of which, the raphe nuclei, project down to the spinal cord. Several pieces of evidence indicate that 5-HT contributes to the control of posture and/or locomotion. Veasey and collaborators (1995) made extracellular single-unit recordings from the nuclei raphe obscurus and raphe pallidus during specific motor activities in freely moving cats. The firing rate of the caudal raphe neurons increased with the treadmill speed, suggesting a causal link between unit activity and motor output, in particular the level of tonic motor activity in antigravity muscles (Jacobs et al., 1997, 2002). It should be mentioned that although intraspinal 5-HT containing neurons are found in all vertebrates (reviewed in Schmidt et al., 2000), the rat is probably one of the species with the least abundant supply of intraspinal 5-HT cells. There are only 3 to 9 such cells in the adult spinal cord. These cells, which appear after birth in the rat, have been suggested to play a role in sympathetic and/or nociceptive functions. Therefore, the 5-HT that is related to the modulation of motor function is provided by axonal projections from the raphe nuclei in the brain stem.

Fibers from the raphe magnus are already present in the lumbar spinal cord at E17 (Lakke, 1997). Fibers from raphe obscurus arrive at E18 and continue to advance down the lumbar cord until E20. Fibers from raphe pallidus arrive later, at E20 in the upper lumbar cord and until P2 in the lower cord. Only a few 5-HT terminals and varicosities are seen in close apposition with half of quadriceps femoris motoneurons at birth whereas at P5, such appositions are found with all the 
motoneurons examined and their number continues to increase. Note, however, that 5-HT is released by growing axons before conventional synapses are established (Gaspar et al., 2003). The adult pattern of 5-HT innervation in the lumbar cord is reached only at P21 (Bregman, 1987. Rajaofetra et al., 1989).

We investigated the functional correlate of the development of descending pathways by means of electrophysiological techniques applied to an in vitro brain stem/spinal cord preparation isolated from neonatal rats (Brocard et al., 1999; Vinay et al., 2000). As a result of the arrival of descending pathways in the lumbar segments, the magnitude of the responses evoked by stimulation of the tracts running in the ventral funiculus increases markedly with age. This increase is such that the percentage of ankle extensor motoneurons recruited (i.e. in which the excitatory post-synaptic potentials reached firing threshold) by a supramaximal ventral funiculus stimulation changes gradually from only $3 \%$ at birth to $35 \%$ at P3-5. This gradual recruitment of ankle extensor motoneurons during the first postnatal week may account for the increased use of the ankle joint in postural reactions during this period (Brocard et al., 1999). Therefore, the influence of those pathways involved in postural control on lumbar motoneurons, in particular those innervating anti-gravity muscles, is weak at birth, and increases markedly during the first postnatal week.

\section{CONTRIBUTIONS OF DESCENDING PATHWAYS TO THE DEVELOPMENT OF POSTURE AND INTERLIM B COORDINATION}

The development of descending pathways not only contributes to the gradual maturation of the supraspinal control of tonic and phasic motoneurons but also has trophic effects on lumbar networks via the neurotransmitters contained in these projections. The monoaminergic pathways, which are among the earliest axonal systems to invade the developing spinal cord (Commissiong, 1983; Kudo et al., 1993; Lakke, 1997), can play such a role (Whitaker-Azmitia, 1991, 1996; Gaspar et al., 2003). Two models were used by our group to investigate the contribution of descending pathways, and in particular serotonergic projections to the maturation of lumbar networks and motoneurons. We used p-chlorophenylalanin (PCPA) to block the synthesis of 5-HT. PCPA was injected intraperitoneally daily from the day of birth. PCPA-treated animals were compared to sham animals from the same litter that were injected every day with saline solution. PCPA decreased the 5-HT levels within a few days as shown by immunohistochemical experiments. The posture of the animals, the motoneuron properties, the network activity were analyzed on the third to fifth postnatal day, therefore after a very short $5-\mathrm{HT}$ depletion (Pflieger et al., 2002). In the second model, the spinal cord was completely transected on the day of birth (Norreel et al., 2003). They were compared with sham-operated rats. The locomotor abilities of these animals were investigated both in vitro and in vivo. The effect of bath applied 5-HT or the effect of injections of 5-HT agonists in vivo were tested to determine whether the activation of 5-HT receptors compensates for the marked locomotor deficits observed in these animals.

The PCPA-treated rats exhibited postural changes characterized by lesser flexion at the knee and ankle levels and lesser extension of the hip (Pflieger et al., 2002). Intracellular recordings were made at P3-5 from motoneurons innervating different hindlimb muscles, using the in vitro brain stem-spinal cord-nerve attached preparation. The 5-HT depletion affected motoneurons differentially, which can alter intra-limb coordination and account partly for the postural and locomotor deficits observed in 5-HT-depleted animals. The excitability of the hip extensor/knee flexor motoneurons was markedly reduced and might be 
responsible for the more rostral placement of the toes in PCPA-treated animals, i.e. lesser extension of the hip. In addition, a larger decrease in excitability in ankle flexor motoneurons compared with ankle extensor motoneurons can account for the hyper-extension of the distal part of the hindlimb. Thus, an important contribution of 5-HT in the rat fetus would be to ensure a ratio between the excitabilities of flexor and extensor motoneurons, thereby preserving the flexed posture that is functionally adapted to the life in utero.

In addition to the alteration of the intra-limb coordination, posture was asymmetric in PCPAtreated animals due to a unilateral hyperextension of the hindlimbs at the ankle and knee levels. The unilateral extension was observed on the left or on the right side, indiscriminately. An asymmetry of posture suggested possible deficits also in the inter-limb coordination (see also Myoga et al., 1995; Nakajima et al., 1998). In agreement with this conclusion, we showed recently that both the left-right and the flexor-extensor alternations observed during fictive locomotion induced by bath application of excitatory amino acids, in vitro, were reduced in PCPA-treated animals, compared with controls (Pearlstein et al., 2005). Interestingly, the locomotor-related left-right alternation is lost a few days after a spinal cord transection is made at birth and recovers after the injection of 5- $\mathrm{HT}_{2}$ receptor agonists in vivo or the bath application of 5-HT in vitro (Norreel et al., 2003). Altogether, these observations suggest that the arrival of 5-HT projections in the lumbar cord is critical for the development of motor coordination.

Spontaneous activity, an intrinsic characteristic of developing networks (reviewed in O'Donovan, 1999 and Ben-Ari, 2001), is believed to contribute to the development of neurons and networks (Vinay et al., 2000; 2002). These activities are observed not only in the visual system and the hippocampus but also in the spinal cord. Immature vertebrates indeed exhibit spontaneous limb movements (Narayanan et al., 1971). In vitro, the spinal cord isolated from fetal or neonatal rats generates an intense spontaneous bursting activity that can be recorded from the ventral roots (Nishimaru et al., 1996; Nakayama et al., 1999; Fellippa-Marques et al., 2000). We observed that this spontaneous motor activity was increased after 5-HT depletion (PCPA-treated animals, Pflieger et al., 2002), suggesting that developing spinal networks are sensitive to 5-HT levels.

\section{WHAT CAN THE RAT TEACH US?}

We manipulated the development of descending pathways during the first postnatal week in the rat. To what extent can these observations be extrapolated to human motor development? Although humans are usually considered an altricial (i.e. immature at birth) species, they are neurally advanced at birth relative to other altricial species, such as the rat (Clancy et al., 2001). The time scale used to compare post-natal motor development in Fig. 1 is therefore not applicable to the prenatal maturation of the central nervous system. A different scale must be used. Based on three factors-species, neural events, and primate adjustments-Clancy and co-workers (2001) developed a model enabling to predict for the timing of many neural events in developing mammalian brains. For instance, the peak of neurogenesis in the raphe complex occurs on E12E13 in the rat, which corresponds to gestation day 43 in humans. Based on this model, which unfortunately did not consider the development of supraspinal projections onto the spinal cord, we can speculate that the first postnatal week in the rat, which is critical for the arrival of descending pathways, particularly serotoninergic projections, in the lumbar enlargement corresponds roughly to the fourth month in the human fetus (Fig. 2).

The next question is to what extent the PCPA rat model can be extrapolated to disorders in human development. In other words, is there any 


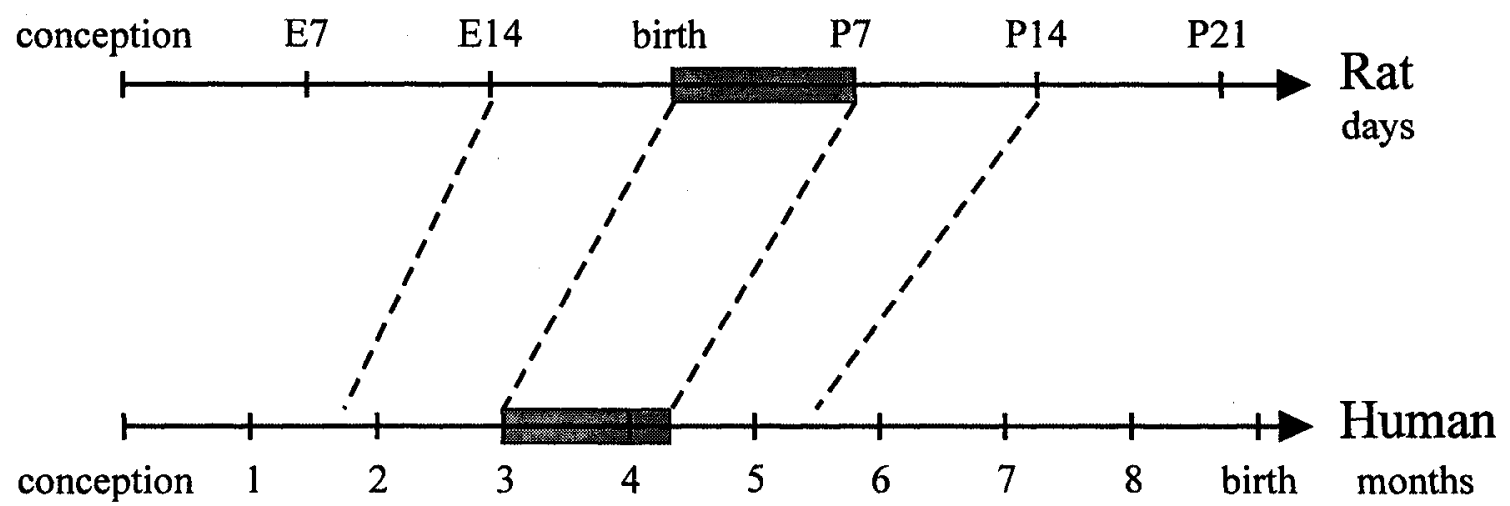

Fig. 2: Schematic comparison between human and rat prenatal neural developments Translation of neural developmental times is based on the model proposed by Clancy et al. (2001). The grey rectangle represents the time window which is critical for the arrival of descending pathways - particularly serotoninergic projections in the lumbar enlargement. The first postnatal week in the rat corresponds roughly to the fourth month in the human fetus

evidence of 5-HT depletion in children? It has been shown that several factors, such as malnutrition (Blatt et al., 1994; Manjarrez et al., 1996), hypoxia (Kim et al., 1994), stress (Smythe et al., 1994), maternal consumption of cocaine (WhitakerAzmitia, 1998), and alcohol (Druse et al., 1991; Kim et al., 1997; Sari et al., 2001) can reduce 5-HT levels markedly in the developing animal. This 5 -HT reduction is likely responsible, at least partly, for the important deficits observed in cognitive functions. Unfortunately, the motor outcomes have not been investigated. However, our results, showing for the first time the effects of 5-HT depletion on the development of spinal cord motoneurons and networks in mammals, would predict that such disturbances affecting 5-HT levels in the developing central nervous system have long-term severe sequels on the motor development of the child, especially deficits in the development of standing and walking.

The human fetus and neonate have a rich repertoire of spontaneous movements (Prechtl, 2001). These spontaneous, endogenously generated activities are believed to play a key role in different developmental processes through the $\mathrm{Ca}^{2+}$ oscillations they trigger in neurons (reviewed in Vinay et al., 2000). Several activity-dependent processes (Demerens et al., 1996) are sensitive to the frequency of $\mathrm{Ca}^{2+}$ oscillations. For example, myelination has been related to the level of spontaneous activity (Stevens et al., 1998). Altered spontaneous activities after 5-HT depletion (Pflieger et al., 2002) can therefore influence neuronal development. Part of the effect of 5-HT depletion on motor development is likely exerted through a modulation of activity-dependent processes.

\section{CONCLUSION}

The major conclusion of this article is that abnormalities in motor control observed in childhood-e.g. deficits in motor coordinationmight have their roots in the prenatal period, in particular 5-HT depletion due to exposure to several environmental and toxicological factors 
during pregnancy. This strengthens the need for medical staff to investigate the prenatal history of patients to make a diagnosis on early motor dysfunction; hence, specific treatments might then be considered.

\section{REFERENCES}

Altman J, Sudarshan K. 1975. Postnatal development of locomotion in the laboratory rat. Anim Behav 23: 896-920.

Auclair F, Bélanger M-C, Marchand R. 1993. Ontogenetic study of early brain stem projections to the spinal cord in the rat. Brain Res Bull 30: 281-289.

Ben-Ari Y. 2001. Developing networks play a similar melody. Trends Neurosci 24: 353-360.

Blatt GJ, Chen JC, Rosene DL, Volicer L, Galler JR. 1994. Prenatal protein malnutrition effects on the serotonergic system in the hippocampal formation: an immunocytochemical, ligand binding, and neurochemical study. Brain Res Bull 34: 507518.

Bregman BS. 1987. Development of serotonin immunoreactivity in the rat spinal cord and its plasticity after neonatal spinal cord lesions. Brain Res 431: 245-263.

Brocard, F., Vinay, L. and Clarac, F. 1999. Gradual development of the ventral funiculus input to lumbar motoneurons in the neonatal rat. Neuroscience 90 : 1543-1554.

Brocard F, Vinay L, Clarac F. 1999. Development of hindlimb postural control during the first postnatal week in the rat. Dev Brain Res 117: 81-89.

Cazalets JR, Menard I, Crémieux J, Clarac F. 1990. Variability as a characteristic of immature motor systems: an electromyographic study of swimming in the newborn rat. Behav Brain Res 40: 215-225.

Clancy B, Darlington RB, Finlay BL. 2001. Translating developmental time across mammalian species. Neuroscience 105: 7-17.

Commissiong JW. 1983. Development of catecholamineergic nerves in the spinal cord of the rat. Brain Res 264: 197-208.

Dahlstrom A, Fuxe K. 1964. Localization of monoamines in the lower brain stem. Experientia 20: 398-399.

Demerens C, Stankoff B, Logak M, Anglade P, Allinquant B, Couraud $F$ et al. 1996. Induction of myelination in the central nervous system by electrical activity. Proc Natl Acad Sci USA 93: 9887-9892.

Donatelle JM. 1977. Growth of the corticospinal tract and the development of placing reactions in the postnatal rat. J Comp Neurol 175: 207-232.

Druse MJ, Kuo A, Tajuddin N. 1991. Effects of in utero ethanol exposure on the developing serotonergic system. Alcohol Clin Exp Res 15: 678-684.

Fellippa-Marques S, Vinay L, Clarac F. 2000. Spontaneous and locomotor-related GABAergic input onto primary afferents in the neonatal rat. Eur J Neurosci 12: 155-164.

Gaspar P, Cases O, Maroteaux L. 2003. The developmental role of serotonin: news from mouse molecular genetics. Nat Rev Neurosci 4: 1002-1012.

Geisler HC, Westerga J, Gramsbergen A. 1993. Development of posture in the rat. Acta Neurobiol Exp (Warsz). 53: 517-523.

Grillner S. 1981. Control of locomotion in bipeds, tetrapods, and fish. In: Brookhart JM, Mountcastle VB, eds, Handbook of Physiology-The nervous system II. Bethesda, Maryland, USA: American Physiological Society; 1179-1236.

Jacobs BL, Fornal CA. 1997. Serotonin and motor activity. Curr Opin Neurobiol 7: 820-825.

Jacobs BL, Martin-Cora FJ, Fornal CA. 2002. Activity of medullary serotonergic neurons in freely moving animals. Brain Res Brain Res Rev 40: 45-52.

Joosten EA, Bar PR, Gispen WH. 1994. Corticospinal axons and mechanism of target innervation in rat lumbar spinal cord. Dev Brain Res 79: 122127.

Kim CS, Mcnamara MC, Lauder JM, Lawson EE. 1994. Immunocytochemical detection of serotonin content in raphe neurons of newborn and young adult rabbits before and after acute hypoxia. Int $J$ Dev Neurosci 12: 499-505.

Kim JA, Gillespie RA, Druse MJ. 1997. Effects of maternal ethanol consumption and buspirone treatment on 5-HT1A and 5-HT2A receptors in offspring. Alcohol Clin Exp Res 21: 1169-1178.

Kudo N, Furukawa F, Okado N. 1993. Development of descending fibers to the rat embryonic spinal cord. Neurosci Res 16: 131-141.

Lakke EAJF. The projections to the spinal cord of the rat during development. a time-table of descent. Adv Anat Embryol Cell Biol 1997.135: 1-143.

Leong SK, Shieh JY, Wong WC. 1984. Localizing spinal-cord-projecting neurons in neonatal and 
immature albino rats. J Comp Neurol 228: 18-23.

Manjarrez GG, Magdaleno VM, Chagoya G, Hernandez J. 1996. Nutritional recovery does not reverse the activation of brain serotonin synthesis in the ontogenetically malnourished rat. Int $\mathrm{J}$ Dev Neurosci 14: 641-648.

McEwen ML, Van Hartesveldt C, Stehouwer DJ. 1997. A kinematic comparison of L-DOPA-induced airstepping and swimming in developing rats. Dev Psychobiol 30: 313-327.

Myoga H, Nonaka S, Matsuyama K, Mori S. 1995. Postnatal development of locomotor movements in normal and para-chlorophenylalanine-treated newborn rats. Neurosci Res 21:211-221.

Nakajima K, Matsuyama K, Mori S. 1998. Prenatal administration of para-chlorophenylalanine results in suppression of serotonergic system and disturbance of swimming movements in newborn rats. Neurosci Res 31: 155-169.

Nakayama K, Nishimaru H, lizuka M, Ozaki S, Kudo N. 1999. Rostrocaudal progression in the development of periodic spontaneous activity in fetal rat spinal motor circuits in vitro. J Neurophysiol 81 : 2592-2595.

Narayanan CH, Fox MW, Hamburger V. 1971. Prenatal development of spontaneous and evoked activity in the rat (Rattus norvegicus albinus). Behavior 40: 100-134.

Newman DB. 1995. Anatomy and neurotransmitters of brainstem motor systems. In: Fahn $\mathrm{S}$, Hallett $\mathrm{M}$, Ludders HO, Marsden CD, eds, Negative Motor Phenomena. Philadelphia, Pennsylvania, USA: Lippincott-Raven Pub; 219-244.

Nishimaru H, Iizuka M, Ozaki S, Kudo N. 1996. Spontaneous motoneuronal activity mediated by glycine and GABA in the spinal cord of rat fetuses in vitro. J Physiol 497: 131-143.

Norreel J-C, Pflieger J-F, Pearlstein E, Simeoni-Alias J, Clarac F, Vinay L. 2003. Reversible disorganization of the locomotor pattern after neonatal spinal cord transection in the rat. $\mathrm{J}$ Neurosci 23: 1924-1932.

O'Donovan MJ. 1999. The origin of spontaneous activity in developing networks of the vertebrate nervous system. Curr Opin Neurobiol 9: 94-104.

Pearlstein E, Ben-Mabrouk F, Pflieger J-F, Vinay L. 2005. Serotonin refines the locomotor-related alternations in the in vitro neonatal rat spinal cord. Eur J Neurosci 21: 1338-1346.

Pflieger JF, Clarac F, Vinay L. 2002. Postural modifications and neuronal excitability changes induced by a short-term serotonin depletion during neonatal development in the rat. $J$ Neurosci 22: 5108-5117.

Prechtl HF. 2001. Prenatal and early postnatal development of human motor behavior. In Kalverboer AF, Gramsbergen A, eds, Handbook of Brain and Behavior in Human Development. Dordrecht, the Netherlands: A. Kluwer Academic Publishers; 415-428.

Rajaofetra N, Sandillon F, Geffard M, Privat A. 1989. Pre- and post-natal ontogeny of serotonergic projections to the rat spinal cord. J Neurosci Res 22: 305-321.

Rossignol S. 1996. Neural control of stereotypic limb movements. In: Rowell LB, Sheperd JT, eds, Handbook of Physiology, Section 12. Exercise: regulation and integration of multiple systems. American Physiological Society.

Sari Y, Powrozek T, Zhou FC. 2001. Alcohol deters the outgrowth of serotonergic neurons at midgestation. J Biomed Sci 8: 119-125.

Schmidt BJ, Jordan LM. 2000. The role of serotonin in reflex modulation and locomotor rhythm production in the mammalian spinal cord. Brain Res Bull 53: 689-710.

Schreyer DJ, Jones EG. 1982. Growth and target finding by axons of the corticospinal tract in prenatal and postnatal rats. Neuroscience $7: 1837-1853$.

Smythe JW, Rowe WB, Meaney MJ. 1994. Neonatal handling alters serotonin (5-HT) turnover and 5HT2 receptor binding in selected brain regions: relationship to the handling effect on glucocorticoid receptor expression. Brain Res Dev Brain Res 80: 183-189.

Stevens B, Tanner S, Fields RD. 1998. Control of myelination by specific patterns of neural impulses. J Neurosci 18: 9303-9311.

Veasey SC, Fornal CA, Metzler CW, Jacobs BL. 1995. Response of serotonergic caudal raphe neurons in relation to specific motor activities in freely moving cats. J Neurosci 15: 5346-5359.

Vinay L, Brocard F, Pflieger JF, Simeoni-Alias J, Clarac F. 2000. Perinatal development of lumbar motoneurons and their inputs in the rat. Brain Res Bull 53: 635-647.

Vinay L, Brocard F, Clarac F, Norreel JC, Pearlstein E, Pflieger JF. 2002. Development of posture and locomotion: an interplay of endogenously generated activities and neurotrophic actions by descending pathways. Brain Res Rev 40: 118-129.

Westerga J, Gramsbergen A. 1990. The development 
of locomotion in the rat. Dev Brain Res 57: 163-174.

Whitaker-Azmitia PM. 1991. Role of serotonin and other neurotransmitter receptors in brain development: basis for developmental pharmacology. Pharmacol Rev 43: 553-561.

Whitaker-Azmitia PM. 1998. Role of the neuro- trophic properties of serotonin in the delay of brain maturation induced by cocaine. Ann NY Acad Sci 846: 158-164.

Whitaker-Azmitia PM, Druse M, Walker P, Lauder JM. 1996. Serotonin as a developmental signal. Behav Brain Res 73: 19-29. 

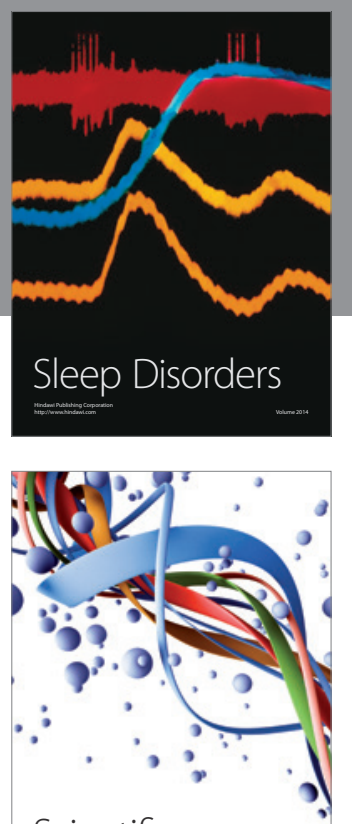

Scientifica
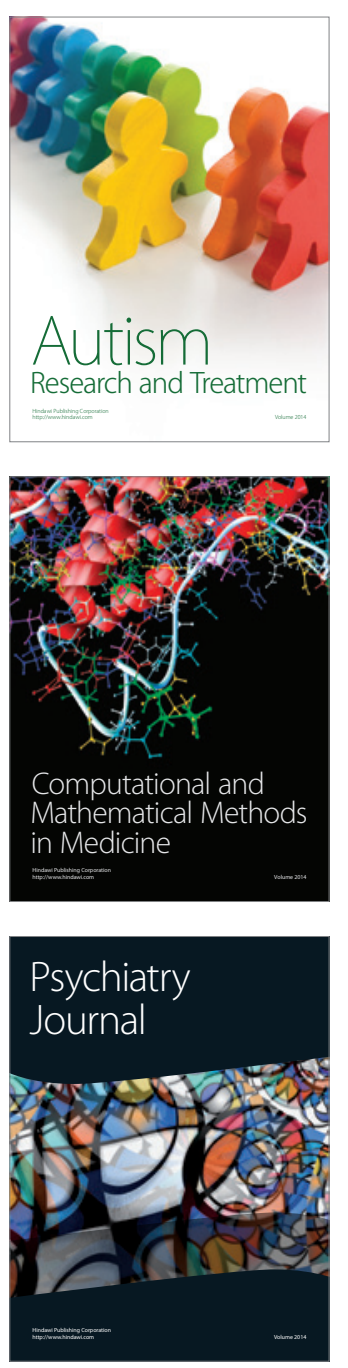
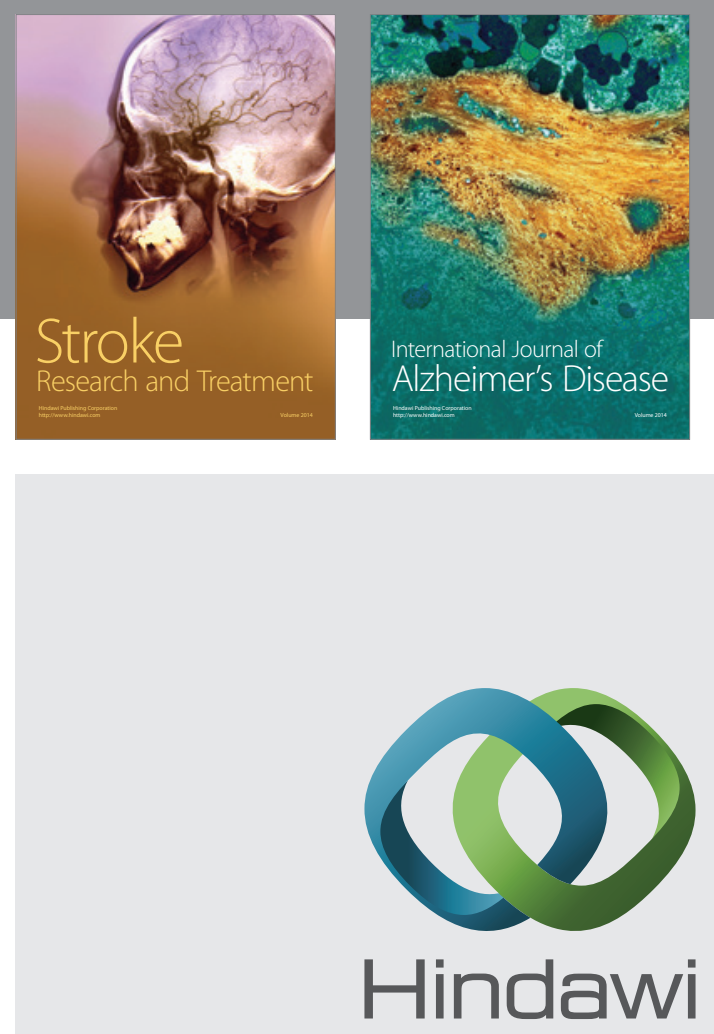

Submit your manuscripts at

http://www.hindawi.com
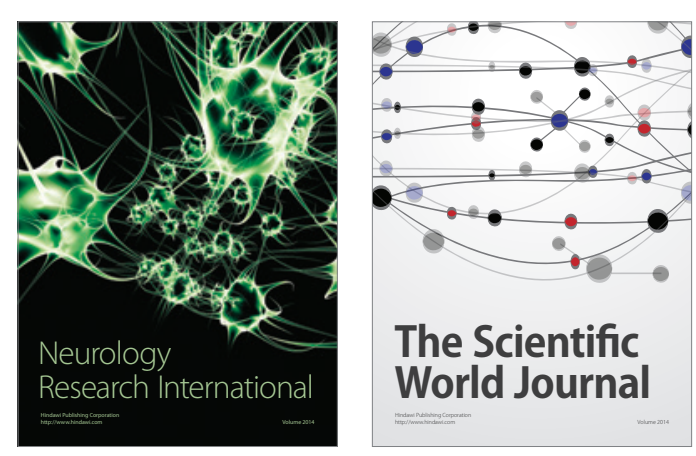

The Scientific World Journal

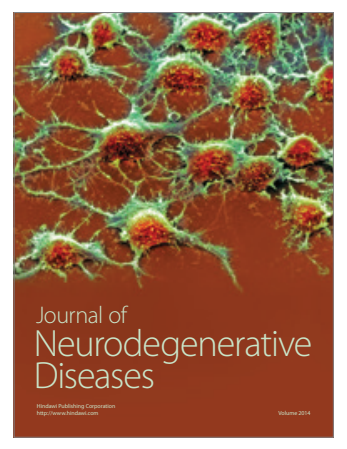

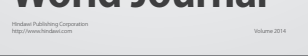

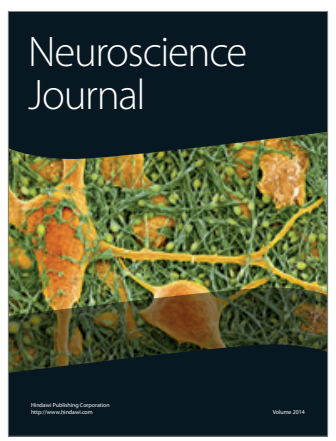

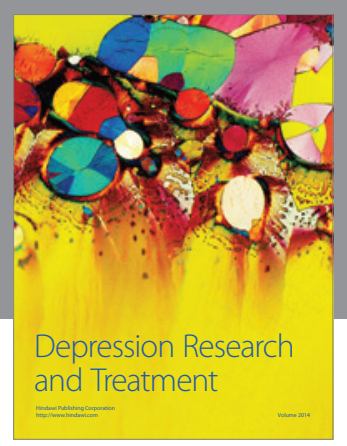
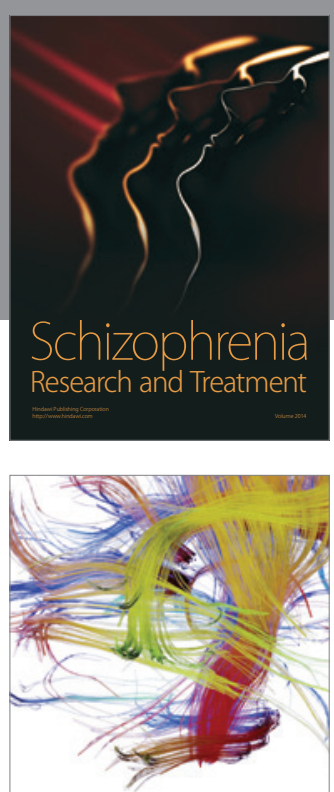

Brain Science

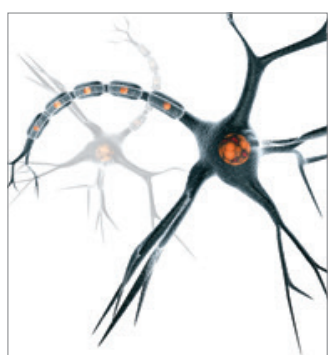

Neural Plasticity
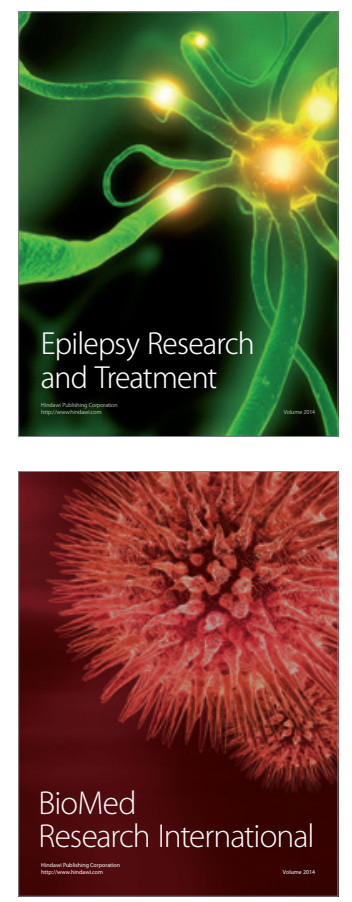

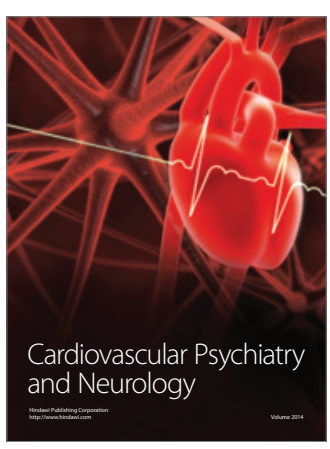

Parkinson's

Disease
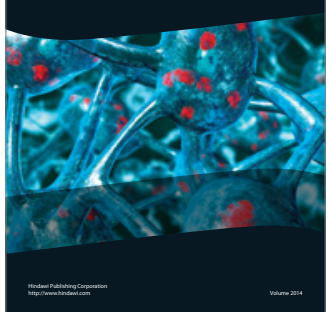